\title{
Fenoterol did not enhance glucocorticoid-induced skeletal changes in male rats ${ }^{\star}$
}

\author{
Joanna Folwarczna ${ }^{凶}$, Barbara Nowińska, Leszek Śliwiński, Maria Pytlik, Urszula Cegieła and \\ Anna Betka
}

Department of Pharmacology, Medical University of Silesia, Katowice, Sosnowiec, Poland

\begin{abstract}
Glucocorticoids and $\beta_{2}$-adrenergic receptor agonists are the most commonly used drugs in the treatment of asthma. Both therapies are potentially dangerous to the skeletal system. The aim of the present study was to investigate the effects of fenoterol, a $\beta_{2}$-receptor agonist, on the development of bone changes induced by glucocorticoid (prednisolone) administration in mature male rats. The experiments were carried out on 24-week-old male Wistar rats. The effects of prednisolone 21-hemisuccinate sodium salt ( $7 \mathrm{mg} / \mathrm{kg}$ s.c. daily) or/and fenoterol hydrobromide (1.4 mg/kg i.p. daily), administered for 4 weeks, on the skeletal system were studied. Bone turnover markers, geometric parameters, mass, mass of bone mineral in the tibia, femur and L-4 vertebra, bone histomorphometric parameters and mechanical properties of tibial metaphysis, femoral diaphysis and femoral neck were determined. Both prednisolone and fenoterol had damaging effects on the skeletal system of mature male rats. However, concurrent administration of fenoterol and prednisolone did not result in the intensification of the deleterious skeletal effect of either drug administered separately.
\end{abstract}

Keywords: fenoterol, prednisolone, bone histomorphometry, bone mechanical properties, bone mineralization

Received: 10 November, 2010; revised: 01 July, 2011; accepted: 19 August, 2011; avialable on-line: 31 August, 2011

\section{INTRODUCTION}

Glucocorticoids and $\beta_{2}$-adrenergic receptor agonists are the most important drugs used in the treatment of asthma and chronic obstructive pulmonary disease (Chung et al., 2009). Patients often use drugs of both groups concurrently. Both therapies are potentially dangerous to the skeletal system.

An excess of glucocorticoids is well-known to affect the skeletal system, predominantly due to the inhibition of bone formation (Dalle Carbonare et al., 2005; Canalis et al., 2007; de Nijs, 2008). Glucocorticoid-induced osteoporosis is the most common form of secondary osteoporosis (Canalis et al., 2007; van Brussel et al., 2009).

Recent years have revealed a role of the sympathetic nervous system in the regulation of bone metabolism. Genetic and pharmacological experiments have demonstrated that activation of $\beta_{2}$-adrenergic receptors in osteoblasts/stromal cells leads to inhibition of trabecular bone formation and intensification of bone resorption (for reviews see Togari \& Arai, 2008; Takeda \& Karsenty, 2008; Hamrick \& Ferrari, 2008). Deleterious effects of salbutamol or clenbuterol, $\beta_{2}$-adrenergic receptor agonists, on the skeletal system of rats (Cavalié et al., 2002; Bonnet et al., 2005; 2007a; 2007b; ), and of isoprenaline, a non-specific $\beta$-adrenergic agonist, on the skeletal system of mice (Takeda et al., 2002; Kondo \& Togari, 2011) have been reported. However, the problem is more complex, as $\beta_{2}$-agonists exert also anabolic effects on the skeletal muscle (Ryall et al., 2004; Beitzel et al., 2004), and increased muscle strength due to increased muscle mass usually leads to bone anabolic effect (Bonnet et al., 2007b; Stuermer et al., 2010). There are also reports on their favorable skeletal effects (Zeman et al. 1991; Radzki et al., 2006; Śliwiński et al., 2008). In humans, populationbased case-control studies have indicated that treatment with $\beta$-agonists may be connected with increased fracture risk (de Vries et al., 2007b; Vestergaard et al., 2007)

Effects of concurrent administration of glucocorticoids and $\beta_{2}$-adrenomimetics on the skeletal system in experimental conditions have not been reported so far. The aim of the present study was to investigate the effects of fenoterol, a $\beta_{2}$-receptor agonist, on the development of bone changes induced by glucocorticoid (prednisolone) administration in mature male rats.

\section{MATERIALS AND METHODS}

Experiments were carried out on mature (24-weekold) male Wistar rats, purchased from the Center of Experimental Medicine, Medical University of Silesia. The rats were fed a standard diet ad libitum. The procedure of the experiments on animals was approved by the Local Ethics Commission, Katowice, Poland.

Drugs used: fenoterol hydrobromide (Sigma-Aldrich, at a dose of $1.4 \mathrm{mg} / \mathrm{kg}$ i.p. daily), prednisolone 21-hemisuccinate sodium salt (Sigma-Aldrich, at a dose of $7 \mathrm{mg} / \mathrm{kg}$ s.c. daily).

The animals were divided into four groups $(n=8-9)$ : I. Control rats, II. Rats receiving prednisolone, III. Rats receiving fenoterol, IV. Rats receiving prednisolone and fenoterol. The drugs were administered once daily for 4 weeks. Each rat from groups I-IV was given two injections: one s.c. (prednisolone or vehicle - $0.9 \% \mathrm{NaCl}$ solution, at a volume of $1 \mathrm{ml} / \mathrm{kg}$ ) and one i.p. (fenoterol or $0.9 \% \mathrm{NaCl}$ solution, at a volume of $1 \mathrm{ml} / \mathrm{kg}$ ). The dose of fenoterol was based on studies of Beitzel et al. (2004; 2007), the dose of prednisolone was similar to or

\footnotetext{
\e-mail: jfolwarczna@sum.edu.pl
$\star$ Preliminary results of the study were presented during 37th European Symposium on Calcified Tissues, 26-30. 06. 2010, Glasgow
} 
the same as used in our previous studies to exert skeletal effects (Folwarczna et al., 1999; 2007).

One day before the start and on the last day of administration of the drugs or the vehicle, the animals were given tetracycline hydrochloride (20 mg/kg i.p.) in order to mark the calcification front. Tetracycline hydrochloride was used as a histomorphometric fluorescence marker (Milch et al., 1958). The next day after the last drug administration, the animals were anesthetised with ketamine and xylazine, and sacrificed after collection of blood samples by heart puncture. The tibias, femurs and L-4 vertebra were isolated. The left tibias, left femurs and proximal part of the right femurs were wrapped in gauze moisturized with $0.9 \% \mathrm{NaCl}$ solution and kept below $-20^{\circ} \mathrm{C}$ until the mechanical tests were performed (Turner \& Burr, 1993). Mass of the adrenal glands was also determined.

Bone mechanical properties studies. Mechanical properties of tibial metaphysis and femoral diaphysis (in bending tests) and femoral neck (in a compression test) were assessed using a single-column materials testing system, model 3342, capacity $500 \mathrm{~N}$, Instron. The data were analysed by Bluehill 2, version 2.14 software (Instron). The software continuously recorded (sampling rate of $100 \mathrm{~Hz}$ ) the displacement of the bone and the load (force) applied to the bone. Analysis of the load-displacement curves in bending tests allowed for determination of the maximal load sustained by the bone, the displacement of the bone for the maximal load (determined as the distance between the initial position of the crosshead and the position of the crosshead when the maximal load was applied) and the energy absorbed by the bone during the measurement to the point when the maximal load was applied (determined as the area under the load-displacement curve).

Mechanical properties of proximal left tibial metaphyses were studied using a bending test with three-point loading, according to the method of Stürmer et al. (2006). Shortly, the proximal epiphysis was removed and the load was applied perpendicularly to the long axis of the tibia, $3 \mathrm{~mm}$ from the edge of the proximal metaphysis. To fix the tibia, a preload of $1 \mathrm{~N}$ was applied, and then the mechanical test was started with a displacement rate of $0.02 \mathrm{~mm} / \mathrm{s}$. Maximal load, displacement for the maximal load and energy for the maximal load were determined.

Mechanical properties of the right femoral neck were studied using a compression test. The bone was prepared for the measurement by fixing the diaphysis, which was cut in mid-length of the femur, in a methacrylate plate. The load was applied to the head of the femur along the long axis of the femur (Folwarczna et al., 2004b; Pytlik et al. 2004). After a preload of $1 \mathrm{~N}$, the mechanical test was started with a displacement rate of $0.01 \mathrm{~mm} / \mathrm{s}$. The load causing fracture of the femoral neck (maximal load) was determined.

Mechanical properties of the diaphysis of the left femurs were studied using a bending test with three-point loading (Turner \& Burr, 1993), using a miniature three-point bend fixture, Instron. The distance between the supporting points was $20 \mathrm{~mm}$. The load was applied perpendicularly to the long axis of the femur in the mid-length of the bone. To obtain steady positioning, five cycles of pre-conditioning (displacement rate of $0.01 \mathrm{~mm} / \mathrm{s}, 4 \mathrm{~N}$ limit) were performed (Westbroek et al., 2007), and then the mechanical test was started (displacement rate of $0.02 \mathrm{~mm} / \mathrm{s}$ ). Maximal load, displacement for the maximal load and energy for the maximal load were assessed.

Bone mass and mineralization studies. The left bones and L-4 vertebra were weighed immediately after isolation (using an analytical AS-200 balance, Ohaus, accu- racy of $0.1 \mathrm{mg}$ ), and macrometric parameters of the long bones were determined (length, diameter of the diaphysis in mid-length). The L-4 vertebra, left tibia and femur were lyophilized for 5 days (FreeZone 6 lyophilizer, Labconco) and weighed in order to determine the dehydrated bone mass. To determine the mass of bone mineral, the bones were mineralized at $640^{\circ} \mathrm{C}$ for $48 \mathrm{~h}$ in a muffle furnace (L9/11/C6, Nabertherm) and weighed. To examine whether the changes in bone mass parameters were related to the changes in the body mass caused by the treatments, results concerning bone mass, lyophilized bone mass and mass of bone mineral were also determined as their ratios to the body mass. The ratios of bone mineral mass to bone mass as well as to lyophilized bone mass were determined as substitutes for bone mineral density measurements.

Calcium content in the mineralized bones (dissolved in $6 \mathrm{M} \mathrm{HCl}$ and then diluted in distilled water) was determined colorimetrically, using a calcium reagent set produced by Pointe Scientific (catalog number C7508). The method was based on the reaction of calcium with $o$-cresolphthalein complexone.

Bone histomorphometric studies. The right femoral and tibial bones were used to prepare histological specimens, as previously described (Folwarczna et al., 1999; 2004a). Histomorphometric measurements were made using an Optiphot-2 microscope (Nikon), connected through an RGB camera (Cohu, mod. 22521040) to a personal computer, using Lucia G 4.51 software (Laboratory Imaging), with final magnifications of 200 and 500 times, and a lanameter (MP-3, PZO, magnification 50×).

In the longitudinal preparation from the femur, the width of trabeculae in the distal epiphysis and metaphysis, and the width of epiphyseal cartilage were measured. In transverse cross-sections made from the femoral diaphysis in mid-length of the femur, the area of the transverse cross-section of the cortical bone and the area of the transverse cross-section of the marrow cavity were determined. In transverse cross-sections made from the tibial diaphysis, the periosteal and endosteal transverse growth, and the width of endosteal osteoid were measured.

Biochemical studies. Serum osteocalcin was determined using enzyme immunoassay (Rat-MID ${ }^{\mathrm{TM}}$ Osteocalcin EIA, Immunodiagnostic Systems Ltd). Osteoclastderived serum tartrate-resistant acid phosphatase form 5b (TRACP 5b) was determined by a solid phase immunofixed enzyme activity assay (RatTRAPTM Assay, Immunodiagnostic Systems Ltd).

Statistical analysis. Results are presented as means \pm S.E.M. Statistical analysis of the results was performed using STATISTICA 7 software (StatSoft). Oneway ANOVA followed by Duncan's test were used for evaluation of statistical significance of the results. In cases of a lack of normality (Shapiro-Wilk's test) or of homogeneity of variance (Levene's test), non-parametric Kruskal-Wallis ANOVA followed by Mann-Whitney U test were performed. The results obtained in each experimental group were compared with those of the control rats. Moreover, the results obtained in the group of rats receiving prednisolone and fenoterol were compared with those of rats receiving prednisolone or fenoterol alone.

\section{RESULTS}

\section{Effects of prednisolone}

Administration of prednisolone to male rats significantly decreased the body mass gain and caused adre- 
Table 1. Effects of prednisolone and fenoterol on the body mass gain and mass of adrenal glands in rats

\begin{tabular}{lllll}
\hline Parameter/Group & Control & Prednisolone & Fenoterol & Prednisolone + Fenoterol \\
\hline $\begin{array}{l}\text { Body mass at the start of drug } \\
\text { administration [g] }\end{array}$ & $359.9 \pm 8.1$ & $362.4 \pm 11.0$ & $354.5 \pm 15.2$ & $355.7 \pm 12.5$ \\
Body mass gain after 4 weeks [g] & $15.0 \pm 5.8$ & $-5.6 \pm 4.4^{*}$ & $35.3 \pm 4.4^{*}$ & $1.4 \pm 5.9^{\mathrm{bbb}}$ \\
Adrenal mass [g] & $0.047 \pm 0.003$ & $0.034 \pm 0.003^{*}$ & $0.041 \pm 0.004$ & $0.035 \pm 0.005^{*}$ \\
\hline
\end{tabular}

Prednisolone 21-hemisuccinate sodium salt (7 mg/kg s.c. daily) and fenoterol hydrobromide (1.4 mg/kg i.p. daily) were administered for 4 weeks. Results are presented as means \pm S.E.M. $(n=8-9)$. One-way ANOVA followed by Duncan's test were used for evaluation of the significance of the results. ${ }^{*} p<0.05$, significantly different from control rats. ${ }^{\text {bbb }} p<0.001$, significantly different from rats receiving fenoterol.

Table 2. Effects of prednisolone and fenoterol on bone mass and mineralization in rats

\begin{tabular}{|c|c|c|c|c|c|}
\hline Parameter/Group & & Control & Prednisolone & Fenoterol & Prednisolone + Fenoterol \\
\hline \multirow{2}{*}{$\begin{array}{l}\text { Bone mass / body mass } \\
\text { [g/100 } \mathrm{g} \text { of body mass] }\end{array}$} & Femur & $0.285 \pm 0.004$ & $0.290 \pm 0.003$ & $0.266 \pm 0.003^{* *}$ & $0.286 \pm 0.009$ \\
\hline & L-4 vertebra & $0.090 \pm 0.002$ & $0.093 \pm 0.002$ & $0.082 \pm 0.003$ & $0.086 \pm 0.005$ \\
\hline \multirow{2}{*}{$\begin{array}{l}\text { Lyophilized bone mass } \\
\text { / body mass [g/100 } \mathrm{g} \text { of } \\
\text { body mass] }\end{array}$} & Femur & $0.199 \pm 0.003$ & $0.203 \pm 0.002$ & $0.187 \pm 0.003^{*}$ & $0.198 \pm 0.005$ \\
\hline & L-4 vertebra & $0.057 \pm 0.001$ & $0.060 \pm 0.002$ & $0.053 \pm 0.001$ & $0.056 \pm 0.003$ \\
\hline \multirow{2}{*}{$\begin{array}{l}\text { Bone mineral mass / } \\
\text { body mass }[\mathrm{g} / 100 \mathrm{~g} \text { of } \\
\text { body mass] }\end{array}$} & Femur & $0.121 \pm 0.002$ & $0.125 \pm 0.001$ & $0.117 \pm 0.002$ & $0.122 \pm 0.003$ \\
\hline & L-4 vertebra & $0.032 \pm 0.001$ & $0.034 \pm 0.001$ & $0.031 \pm 0.001$ & $0.032 \pm 0.001$ \\
\hline \multirow{2}{*}{$\begin{array}{l}\text { Bone mineral mass / } \\
\text { bone mass ratio }\end{array}$} & Femur & $0.425 \pm 0.005$ & $0.433 \pm 0.004$ & $0.441 \pm 0.005$ & $0.432 \pm 0.010$ \\
\hline & L-4 vertebra & $0.360 \pm 0.007$ & $0.365 \pm 0.005$ & $0.382 \pm 0.012$ & $0.383 \pm 0.014$ \\
\hline \multirow{2}{*}{$\begin{array}{l}\text { Bone mineral mass / } \\
\text { lyophilized bone mass } \\
\text { ratio }\end{array}$} & Femur & $0.609 \pm 0.007$ & $0.617 \pm 0.005$ & $0.626 \pm 0.003$ & $0.616 \pm 0.005$ \\
\hline & L-4 vertebra & $0.563 \pm 0.007$ & $0.565 \pm 0.004$ & $0.586 \pm 0.006$ & $0.579 \pm 0.010$ \\
\hline Femur length [mm] & & $40.42 \pm 0.29$ & $39.81 \pm 0.26$ & $39.87 \pm 0.41$ & $39.51 \pm 0.43$ \\
\hline Femur diameter $[\mathrm{mm}]$ & & $3.91 \pm 0.04$ & $3.82 \pm 0.05$ & $3.88 \pm 0.09$ & $3.80 \pm 0.09$ \\
\hline
\end{tabular}

Prednisolone 21-hemisuccinate sodium salt ( $7 \mathrm{mg} / \mathrm{kg}$ s.c. daily) and fenoterol hydrobromide $(1.4 \mathrm{mg} / \mathrm{kg}$ i.p. daily) were administered for 4 weeks. Results are presented as means \pm S.E.M. ( $n=8-9)$. One-way ANOVA followed by Duncan's test, or, when appropriate, Kruskal-Wallis ANOVA followed by Mann-Whitney $U$ test were used for evaluation of the significance of the results. ${ }^{*} p<0.05,{ }^{* *} p<0.01$, significantly different from control rats.

nal gland atrophy (Table 1), but it did not significantly affect the mass of bones immediately after isolation, mass of lyophilized bones or mass of bone mineral in comparison with the control group (not shown). The ratios of bone mass, lyophilized bone mass and bone mineral mass to the body mass and the ratio of bone mineral mass to bone mass slightly tended to increase or were unaffected (Table 2, data for the tibia not shown). Calcium content in the bone mineral was not affected (not shown).
The mechanical properties of cancellous bone of the tibial metaphysis in rats receiving prednisolone were significantly impaired: the displacement for the maximal load and the energy for the maximal load were decreased, and the maximal load slightly tended to decrease in comparison with the controls (Table 3). Prednisolone administration did not affect the mechanical properties of the femoral diaphysis or the femoral neck.

In the cancellous bone of the femur, the width of trabeculae was significantly decreased after prednisolone

Table 3. Effects of prednisolone and fenoterol on bone mechanical properties in rats

\begin{tabular}{llllll}
\hline Parameter/Group & & Control & Prednisolone & Fenoterol & Prednisolone + Fenoterol \\
\hline Tibial metaphysis & Maximal load [N] & $98.35 \pm 6.02$ & $91.67 \pm 5.07$ & $96.45 \pm 10.48$ & $100.51 \pm 8.06$ \\
& $\begin{array}{l}\text { Displacement for maximal load } \\
{[\mathrm{mm}]}\end{array}$ & $1.252 \pm 0.096$ & $0.855 \pm 0.056^{* *}$ & $0.850 \pm 0.117^{* *}$ & $1.036 \pm 0.073$ \\
& Energy for maximal load [J] & $0.077 \pm 0.009$ & $0.047 \pm 0.004^{*}$ & $0.052 \pm 0.010^{*}$ & $0.061 \pm 0.006$ \\
& Maximal load [N] & $124.25 \pm 6.17$ & $130.63 \pm 5.39$ & $138.37 \pm 7.83$ & $123.14 \pm 4.08$ \\
Femoral neck & Maximal load [N] & $154.18 \pm 5.77$ & $153.78 \pm 5.78$ & $159.57 \pm 8.12$ & $152.96 \pm 6.49$ \\
Femoral & $\begin{array}{l}\text { Displacement for maximal load } \\
{[\mathrm{mm}]}\end{array}$ & $0.710 \pm 0.028$ & $0.702 \pm 0.035$ & $0.674 \pm 0.024$ & $0.669 \pm 0.030$ \\
& $\begin{array}{l}\text { Energy for maximal load [J] } \\
\text { liaphys }\end{array}$ & $0.070 \pm 0.005$ & $0.069 \pm 0.006$ & $0.067 \pm 0.004$ & $0.065 \pm 0.006$ \\
\hline
\end{tabular}

Prednisolone 21-hemisuccinate sodium salt (7 mg/kg s.c. daily) and fenoterol hydrobromide (1.4 mg/kg i.p. daily) were administered for 4 weeks. Results are presented as means \pm S.E.M. $(n=8-9)$. One-way ANOVA followed by Duncan's test, or, when appropriate, Kruskal-Wallis ANOVA followed by Mann-Whitney $\mathrm{U}$ test were used for evaluation of the significance of the results. ${ }^{*} p<0.05,{ }^{* *} p<0.01$, significantly different from control rats. 
Table 4. Effects of prednisolone and fenoterol on bone histomorphometric parameters in rats

\begin{tabular}{|c|c|c|c|c|c|}
\hline \multicolumn{2}{|l|}{ Parameter/Group } & Control & Prednisolone & Fenoterol & Prednisolone + Fenoterol \\
\hline \multirow{2}{*}{$\begin{array}{l}\text { Width of trabeculae in the } \\
\text { femur }[\mu \mathrm{m}]\end{array}$} & Epiphysis & $54.72 \pm 0.59$ & $42.94 \pm 0.92^{* * *}$ & $45.26 \pm 0.69^{* * *}$ & $44.08 \pm 0.57^{* * *}$ \\
\hline & Metaphysis & $43.55 \pm 0.91$ & $36.84 \pm 0.83^{* * *}$ & $37.02 \pm 0.72^{* * *}$ & $35.96 \pm 1.08^{* * *}$ \\
\hline \multicolumn{2}{|c|}{ Width of epiphyseal cartilage in the femur $[\mu \mathrm{m}]$} & $85.31 \pm 3.81$ & $81.35 \pm 4.82$ & $62.29 \pm 3.56^{* *}$ & $64.50 \pm 4.79 * * a$ \\
\hline \multicolumn{2}{|c|}{$\begin{array}{l}\text { Transverse cross-sectional area of the cortical bone } \\
\text { in the femoral diaphysis }\left[\mathrm{mm}^{2}\right]\end{array}$} & $6.64 \pm 0.28$ & $6.41 \pm 0.18$ & $6.63 \pm 0.20$ & $6.46 \pm 0.32$ \\
\hline \multicolumn{2}{|c|}{$\begin{array}{l}\text { Transverse cross-sectional area of the marrow cavity } \\
\text { in the femoral diaphysis }\left[\mathrm{mm}^{2}\right]\end{array}$} & $4.25 \pm 0.13$ & $3.79 \pm 0.16$ & $4.13 \pm 0.18$ & $3.65 \pm 0.16^{*}$ \\
\hline \multicolumn{2}{|c|}{ Femoral marrow cavity/diaphysis area ratio } & $0.391 \pm 0.010$ & $0.371 \pm 0.013$ & $0.383 \pm 0.007$ & $0.362 \pm 0.009$ \\
\hline \multicolumn{2}{|c|}{ Width of endosteal osteoid in the tibia $[\mu \mathrm{m}]$} & $8.23 \pm 0.22$ & $7.43 \pm 0.24^{*}$ & $6.63 \pm 0.22^{* * *}$ & $6.09 \pm 0.20^{* * * a a}$ \\
\hline \multirow{2}{*}{$\begin{array}{l}\text { Transverse } \\
\text { growth of the } \\
\text { tibia }[\mu \mathrm{m}]\end{array}$} & Periosteal & $22.98 \pm 2.93$ & $14.39 \pm 1.41 *$ & $13.59 \pm 0.93^{*}$ & $11.69 \pm 1.13^{* *}$ \\
\hline & Endosteal & $8.28 \pm 0.29$ & $8.10 \pm 0.30$ & $7.27 \pm 0.22$ & $6.47 \pm 0.67^{* *_{a}}$ \\
\hline
\end{tabular}

Prednisolone 21-hemisuccinate sodium salt (7 mg/kg s.c. daily) and fenoterol hydrobromide (1.4 mg/kg i.p. daily) were administered for 4 weeks. Results are presented as means \pm S.E.M. $(n=8-9)$. One-way ANOVA followed by Duncan's test or, when appropriate, Kruskal-Wallis ANOVA followed by Mann-Whitney U test were used for evaluation of the significance of the results. ${ }^{*} p<0.05,{ }^{* *} p<0.01$, ${ }^{* * *} p<0.001$, significantly different from control rats. a $p<0.05$, aa $p<0.01$, significantly different from rats receiving prednisolone.

administration in relation to the controls (Table 4). In the compact bone, histomorphometric analysis demonstrated a decreased osteoid width, periosteal transverse growth in the tibia and a strong tendency to decrease the transverse cross-sectional area of the femoral marrow cavity.

After prednisolone administration, the serum levels of osteocalcin and TRACP 5b strongly tended to decrease in comparison with the controls (Table 5).

\section{Effects of fenoterol}

Administration of fenoterol significantly increased the body mass gain and did not affect the mass of the adrenal glands (Table 1). The mass of bones immediately after isolation and mass of lyophilized bones slightly tended to decrease in comparison with the control group (not shown), whereas the ratios of bone mass and lyophilized bone mass to the body mass were decreased (significantly in the long bones). The ratios of bone mineral mass to the body mass were less decreased (Table 2, data for the tibia not shown). In consequence, the ratios of bone mineral mass to bone mass or lyophilized bone mass strongly tended to increase. Fenoterol did not affect calcium content in the bone mineral (not shown).

The mechanical properties of the tibial metaphysis after administration of fenoterol were worsened in comparison with controls: the displacement for the maximal load and the energy for the maximal load were significantly decreased in comparison with the control rats (Table 3). There were no significant effects of fenoterol administration on the mechanical properties of the femoral diaphysis or femoral neck.
Fenoterol decreased the width of metaphyseal and epiphyseal trabeculae as well as epiphyseal cartilage in the distal femoral epiphysis (Table 4). The transverse cross-sectional area of the marrow cavity and that of cortical bone, as well as the ratio of transverse cross-sectional area of the marrow cavity to transverse cross-sectional area of the diaphysis in the femur were not significantly affected. However, in the compact bone of the tibia, fenoterol decreased the osteoid width and periosteal tranverse growth.

Administration of fenoterol did not affect serum TRACP 5b level, but it significantly decreased osteocalcin concentration (Table 5).

\section{Effects of concurrent administration of fenoterol and prednisolone}

Fenoterol partially counteracted the catabolic effect of prednisolone on the body mass, and did not affect the adrenal gland atrophy induced by prednisolone (Table 1).

After concurrent administration of fenoterol and prednisolone, the mass of bones immediately after isolation, mass of lyophilized bones and mass of bone mineral tended to decrease in relation to controls (not shown). The ratios of bone mass, lyophilized bone mass and bone mineral mass to the body mass were at the same level as those of the control rats, and increased in comparison with rats receiving fenoterol alone (Table 2, data for the tibia not shown). Calcium content in the bone mineral was not affected (not shown).

Concurrent administration of fenoterol and prednisolone did not statistically significantly affect bone mechanical properties (both cancellous and compact, Table 3).

Table 5. Effects of prednisolone and fenoterol on serum bone turnover markers

\begin{tabular}{lllll}
\hline Parameter/Group & Control & Prednisolone & Fenoterol & Prednisolone + Fenoterol \\
\hline Osteocalcin $[\mathrm{ng} / \mathrm{ml}]$ & $285.9 \pm 19.3$ & $244.5 \pm 17.3$ & $231.4 \pm 18.6^{*}$ & $206.8 \pm 8.1^{* *}$ \\
TRACP 5b [U/l] & $3.08 \pm 0.13$ & $2.45 \pm 0.20$ & $2.93 \pm 0.23$ & $2.56 \pm 0.20$ \\
\hline
\end{tabular}

Prednisolone 21-hemisuccinate sodium salt (7 mg/kg s.c. daily) and fenoterol hydrobromide (1.4 mg/kg i.p. daily) were administered for 4 weeks. Results are presented as means \pm SEM $(n=8-9)$. One-way ANOVA followed by Duncan's test were used for evaluation of the significance of the results. ${ }^{*} p<0.05,{ }^{* *} p<0.01$, significantly different from control rats. 
The histomorphometric parameters of rats receiving both drugs remained similar to those of rats administered fenoterol or prednisolone alone (Table 4). Serum osteocalcin level was significantly decreased, and TRACP 5b level tended to decrease in comparison with controls (Table 5).

\section{DISCUSSION}

Asthma is a chronic inflammatory disease; the most common treatment are inhaled glucocorticoids due to their anti-inflammatory activity (Navarro et al. 2007), which they exert through glucocorticoid receptors. $\beta$-Adrenergic agonists are used because of their bronchodilatory activity through $\beta_{2}$-adrenergic receptors. $\beta_{2}$ Adrenergic agonists also have some anti-inflammatory activity (Lovén et al., 2007).

Adverse effects on the skeleton belong to the most important side effects of glucocorticoid therapy, even in low doses (Mazziotti et al., 2006; de Nijs, 2008). In patients, glucocorticoid-induced osteoporosis occurs in two phases: a rapid, early phase in which bone mineral density is reduced presumably because of increased bone resorption, and a slower, progressive phase in which bone mineral density decreases due to impaired bone formation (Canalis et al., 2007). However, in postmenopausal women, low-dose prednisone has been reported to decrease bone formation markers and to decrease a bone resorption marker (free urinary deoxypyridinoline), indicating also the possibility of inhibition of bone resorption (Ton et al., 2005). Nevertheless, the main effect of glucocorticoids on bone is inhibition of osteoblast number and function, leading to a decrease in bone formation (Canalis et al., 2007). Glucocorticoids exert their activity through cytoplasmic receptors, which, after binding the ligand, affect gene transcription (Chung et al., 2009). Moreover, nongenomic effects mediated by glucocorticoid interactions with biological membranes, either through binding to membrane receptors or by physicochemical interactions, may take part in the pathogenesis of glucocorticoid-induced osteoporosis (de Nijs, 2008).

The rat model of glucocorticoid-induced osteoporosis is not well established (Folwarczna et al., 1999; 2007; Lelovas et al., 2008; Ogoshi et al., 2008). The duration of the drug treatment in the present study (4 weeks) was sufficient to induce significant skeletal changes due to estrogen deficiency, glucocorticoid excess, heparin and other drug treatments in our previous studies (Folwarczna et al., 1999; 2004a; 2004b; Pytlik et al., 2004; Śliwiński et al., 2009). The dose of prednisolone 21-hemisuccinate sodium salt, used in the present study, $7 \mathrm{mg} / \mathrm{kg}$ s.c. daily for 4 weeks, was sufficient to cause adrenal atrophy due to inhibition of the hypothalamus-pituitary-adrenal axis, and to exert a catabolic effect (a decrease in the body mass). Although prednisolone did not significantly affect bone mass, mass of bone mineral or their ratio to the body mass, as well as bone mineralization, it induced skeletal changes, leading to worsening of the mechanical endurance of cancellous bone (tibial metaphyses). Histomorphometric measurements in the cancellous bone of the femur demonstrated that the width of trabeculae decreased, which could be due to a decrease in bone formation and/or an increase in bone resorption. Compact bone formation was inhibited, since decreased periosteal transverse growth and the width of the osteoid in the tibial diaphysis were observed. Bone resorption of the compact bone also seemed to be inhibited, since the cross-sectional area of the femoral marrow cavity strongly tended to decrease. Serum osteocalcin level, a marker of bone formation, and serum TRACP $5 b$ level strongly tended to decrease. The latter marker is an osteoclastic enzyme. Secreted TRACP $5 b$ indicates the number of osteoclasts rather than their activity; it can mirror both decreased bone resorption due to a lower osteoclast number, and a lower number of osteoclasts due to the bone loss induced by prednisolone treatment. Taken together, prednisolone administration caused both inhibition of bone formation and resorption. This conclusion is consistent with the results of Ogoshi et al. (2008) for rats of similar age.

In the treatment of asthma, inhaled corticosteroids are usually prescribed. According to some authors, such medications may be safer for the skeleton than oral ones (de Vries et al., 2007a; Vestergaard et al., 2007). For example, although the risk of hip/femur fracture increased with current use of inhaled glucocorticoids, after adjustment for disease severity, the risk of hip/femur fracture was no longer statistically significantly increased, suggesting that inhaled glucocorticoid use may not be an independent risk factor for fracture (de Vries et al., 2007a). However, asthma patients often use also $\beta_{2}$-adrenergic receptor agonists.

The sympathetic nervous system takes part in regulation of bone metabolism (Elefteriou, 2008; Takeda \& Karsenty, 2008; Hamrick \& Ferrari, 2008). Experimental and some human studies have demonstrated favorable effects of $\beta$-adrenergic receptor antagonists on the skeletal system and they are now considered to be potential drugs under investigation for osteoporosis and fracture healing (Graham et al., 2008). The effects of $\beta$-adrenomimetics on the skeletal tissue are less explored. Little is known about the effects of $\beta$-adrenomimetics on the skeletal system in humans, although the drugs are widely used in the treatment of asthma. A population-based case-control study has indicated an increased risk of hip/femur fracture in patients using higher doses of $\beta_{2}$-agonists (de Vries et al., 2007b). In a case-control study in the Danish population, Vestergaard et al. (2007) found that inhaled short-acting $\beta$-agonists were associated with an increase in fracture risk (dose independent), whereas oral $\beta$-agonists were associated with an increase in fracture risk at low doses but not at higher doses.

Administration of fenoterol hydrobromide $(1.4 \mathrm{mg} /$ $\mathrm{kg}$ i.p. daily for 4 weeks) significantly increased the body mass gain in rats. We did not measure the fat mass or muscle mass, however, according to other investigators, another $\beta_{2}$-agonist, salbutamol, increased only muscle (not fat) mass in female rats (Bonnet et al., 2007a; 2007b). $\beta$-Adrenergic agonists are known to exert anabolic effects on muscles, which is the reason for their use as doping agents by athletes (Bonnet et al., 2005). Prolonged $\beta_{2}$-agonist administration produces muscle hypertrophy and often increases maximum force-producing capacity, due to $\beta_{2}$-adrenergic receptor-mediated protein accretion via increases in intracellular cAMP, promoting both an increase in protein synthesis and a decrease in protein degradation (Beitzel et al., 2004; 2007). The increase of body mass would be expected to increase also bone mass (Hamrick \& Ferrari, 2008). However, this effect was not observed; in fact, the ratios of bone mass and lyophilized bone mass to the body mass were significantly decreased. Nevertheless, the ratios of bone mineral mass to bone mass or lyophilized bone mass strongly tended to increase, since fenoterol affected the mass of bone mineral to a much lower degree than it did the bone mass. Histomorphometric measurements demonstrated that fenoterol significantly 
decreased compact bone formation (transverse growth and osteoid width) and did not significantly affect bone resorption (transverse cross-sectional area of the marrow cavity and its ratio to the cross-sectional area of the diaphysis were not affected). Serum bone turnover marker measurements confirmed the inhibition of bone formation (osteocalcin level) and no effect on the osteoclast number (TRACP 5b level). The observed decrease in the trabeculae width could be the effect of the inhibition of bone formation and/or intensification of bone resorption. The changes caused significant worsening of the mechanical properties of the cancellous bone.

Taken together, results of the present study demonstrated unfavorable effects of fenoterol on both cancellous and compact bone of mature male rats. Our results are to some extent consistent with other reports on deleterious effects of clenbuterol and salbutamol on the skeletal system of rats (Cavalié et al. 2002; Bonnet et al., 2005; 2007a). However, they reported increased bone resorption induced by $\beta_{2}$-adrenergic agonists, which is consistent with the proposed role of sympathetic nervous system in the regulation of bone metabolism (Togari \& Arai, 2008; Takeda \& Karsenty, 2008). Those experiments were performed on female rats (Bonnet et al., 2005; 2007a) or on male rats younger than ours (Cavalié et al. 2002), and the treatment time was longer. It must be pointed out that there are also reports on favorable effects of $\beta$-adrenergic agonists on bones (Zeman et al. 1991; Radzki et al., 2006; Śliwiński et al., 2008).

One of the mechanisms proposed for the anti-inflammatory activity of $\beta_{2}$-agonists is that they have the potential to activate the glucocorticoid receptor in the absence of a glucocorticoid receptor ligand (Lovén et al., 2007). In primary human lung fibroblasts and vascular smooth muscle cells, exposition to $\beta_{2}$-agonists (salbutamol or salmeterol) led to glucocorticoid receptor translocation into the nucleus and binding of the receptors to glucocorticoid responsive elements. The glucocorticoid receptor activation was blocked by propranolol, a $\beta$-receptor antagonist, indicating that the process was $\beta_{2}$ receptor-dependent (Eickelberg et al., 1999). It may be speculated that similar mechanisms in bone cells could contribute to some similarities in the effects of fenoterol and prednisolone on bone turnover markers, histomorphometric parameters and mechanical properties, observed in the present study.

After simultaneous administration of prednisolone and fenoterol to rats, worsening of symptoms of bone damage could have been expected. However, when prednisolone and fenoterol were administered concurrently, the deleterious skeletal effects in most parameters were not increased relative to those of the drugs administered separately. The histomorphometric measurements of compact bone and serum bone turnover markers indicated decreased both bone resorption and formation. Moreover, the unfavorable changes in the most important parameter concerning bone quality - bone mechanical endurance — were insignificantly ameliorated in relation to the rats receiving one of the drugs alone. Also the changes caused by fenoterol alone in the bone mass and bone mineral mass to body mass ratios were not observed any more, and the changes in the ratios of bone mineral mass to bone mass were attenuated. The favorable effect on bone strength may be connected with another target of $\beta_{2}$-adrenomimetics: the muscle.

According to the Frost's theory of muscle-bone interaction, the so-called mechanostat system regulating bone mass is responsible for an anabolic effect on bone tissue induced in response to an increase in muscle strength, possibly associated with a higher muscle mass (Bonnet et al., 2007b). At a normal glucocorticoid level, the direct effects of fenoterol on the bone seemed to surpass the indirect effect which might have been induced by the increased muscle mass. However, the observed amelioration of some deleterious effects of prednisolone by simultaneous administration of fenoterol could have been the result of the above mechanism.

Results of the present study are consistent with the clinical report of Pasaoglu et al. (2006), who observed a non-significant trend towards reducing bone loss with the use of a combination of inhaled corticosteroids with long-acting $\beta_{2}$-agonist therapy in relation to the therapy with single inhaled corticosteroids.

In conclusion, results of the present study indicate a clear potential of $\beta_{2}$-adrenergic agonists to induce damaging effects on the skeletal system, both administered separately and in combination with prednisolone. However, the simultaneous administration of prednisolone and fenoterol did not potentiate the deleterious effect of either drug administered separately.

\section{REFERENCES}

Beitzel F, Gregorevic P, Ryall JG, Plant DR, Sillence MN, Lynch GS (2004) $\beta_{2}$-Adrenoceptor agonist fenoterol enhances functional repair of regenerating rat skeletal muscle after injury. J Appl Physiol 96: 1385-1392.

Beitzel F, Sillence MN, Lynch GS (2007) $\beta$-Adrenoceptor signaling in regenerating skeletal muscle after $\beta$-agonist administration. Am J Physiol Endocrinol Metab 293: E932-E940.

Bonnet N, Benhamou CL, Beaupied H, Laroche N, Vico L, Dolleans E, Courteix D (2007a) Doping dose of salbutamol and exercise: deleterious effect on cancellous and cortical bones in adult rats. J Appl Physiol 102: 1502-1509.

Bonnet N, Benhamou CL, Brunet-Imbault B, Arlettaz A, Horcajada MN, Richard O, Vico L, Collomp K, Courteix D (2005) Severe bone alteration under $\beta_{2}$ agonist treatments: bone mass, microarchitecture and strength analyses in female rats. Bone 37: 622-633.

Bonnet N, Laroche N, Beaupied H, Vico L, Dolleans E, Benhamou CL, Courteix D (2007b) Doping dose of salbutamol and exercise training: impact on the skeleton of ovariectomized rats. J Appl Physiol 103: $524-533$.

Canalis E, Mazziotti G, Giustina A, Bilezikian JP (2007) Glucocorticoid-induced osteoporosis: pathophysiology and therapy. Osteoporos Int 18: 1319-1328.

Cavalié H, Lac G, Lebecque P, Chanteranne B, Davicco MJ, Barlet JP (2002) Influence of clenbuterol on bone metabolism in exercised or sedentary rats. J Appl Physiol 93: 2034-2037.

Chung KF, Caramori G, Adcock IM (2009) Inhaled corticosteroids as combination therapy with $\beta$-adrenergic agonists in airways disease: present and future. Eur J Clin Pharmacol 65: 853-871.

Dalle Carbonare L, Bertoldo F, Valenti MT, Zenari S, Zanatta M, Sella S, Giannini S, Lo Cascio V (2005) Histomorphometric analysis of glucocorticoid-induced osteoporosis. Micron 36: 645-652.

de Nijs RNJ (2008) Glucocorticoid-induced osteoporosis: a review on pathophysiology and treatment options. Minerva Med 99: 23-42.

de Vries F, Pouwels S, Lammers JW, Leufkens HG, Bracke M, Cooper C, van Staa TP (2007a) Use of inhaled and oral glucocorticoids, severity of inflammatory disease and risk of hip/femur fracture: a population-based case-control study. I Intern Med 261: 170-177.

de Vries F, Pouwels S, Bracke M, Leufkens HG, Cooper C, Lammers JW, van Staa TP (2007b) Use of $\beta_{2}$-agonists and risk of hip/femur fracture: a population-based case-control study. Pharmacoepidemiol Drug Saf 16: 612-619.

Elefteriou F (2008) Regulation of bone remodeling by the central and peripheral nervous system. Arch Biochem Biophys 473: 231-236.

Eickelberg O, Roth M, Lörx R, Bruce V, Rüdiger J, Johnson M, Block LH (1999) Ligand-independent activation of the glucocorticoid receptor by $\beta_{2}$-adrenergic receptor agonists in primary human lung fibroblasts and vascular smooth muscle cells. J Biol Chem 274: 1005-1010.

Folwarczna J, Janiec W, Firlus K, Kaczmarczyk-Sedlak I (1999) Effects of doxycycline on the development of bone damage caused by prednisolone in rats. Pol J Pharmacol 51: 243-251. 
Folwarczna J, Janiec W, Gawor M, Pytlik M, Kaczmarczyk-Sedlak I, Nowińska B (2004a) Effects of enoxaparin on histomorphometric parameters of bones in rats. Pol J Pharmacol 56: 451-457.

Folwarczna J, Janiec W, Śliwiński L (2004b) Effects of heparin and low-molecular-weight heparins on bone mechanical properties in rats. Thromb Haemost 92: 940-946.

Folwarczna J, Śliwiński L, Kulig M, Nowińska B, Cegieła U, Pytlik M, Kaczmarczyk-Sedlak I, Trzeciak HI (2007) Effect of propranolol on the glucocorticoid-induced bone changes in young rats. Calcif Tissue Int 80 (Suppl. 1): S126-S127 (abstract).

Frost HM (2004) A 2003 update of bone physiology and Wolffs law for clinicians. Angle Orthod 74: 3-15.

Graham S, Hammond-Jones D, Gamie Z, Polyzois I, Tsiridis E, Tsiridis E (2008) The effect of $\beta$-blockers on bone metabolism as potential drugs under investigation for osteoporosis and fracture healing. Expert Opin Investig Drugs 17: 1281-1299.

Hamrick MW, Ferrari SL (2008) Leptin and the sympathetic connection of fat to bone. Osteoporos Int 19: 905-912.

Kondo H, Togari A (2011) Continuous treatment with a low-dose $\beta$-agonist reduces bone mass by increasing bone resorption without suppressing bone formation. Calcif Tissue Int 88: 23-32.

Lelovas PP, Xanthos TT, Thoma SE, Lyritis GP, Dontas IA (2008) The laboratory rat as an animal model for osteoporosis research. Comp Med 58: 424-430.

Lovén J, Svitacheva N, Jerre A, Miller-Larsson A, Korn SH (2007) Anti-inflammatory activity of $\beta_{2}$-agonists in primary lung epithelial cells is independent of glucocorticoid receptor. Eur Respir J 30: 848-856.

Mazziotti G, Angeli A, Bilezikian JP, Canalis E, Giustina A (2006). Glucocorticod-induced osteoporosis: an udpade. Trends Endocrinol Metab 17: 144-149.

Milch RA, Rall DP, Tobie JE (1958) Fluorescence of tetracycline antibiotics in bone. I Bone Joint Surg Am 40-A: 897-910.

Navarro RP, Schaecher KL, Rice GK (2007) Asthma management guidelines: updates, advances, and new options. J Manag Care Pharm 13 (6 Suppl D): S3-S11.

Ogoshi T, Hagino H, Fukata S, Tanishima S, Okano T, Teshima R (2008) Influence of glucocorticoid on bone in 3-, 6-, and 12-monthold rats as determined by bone mass and histomorphometry. Mod Rheumatol 18: 552-561.

Pasaoglu G, Gok H, Mungan D, Sonel B, Yalcin P, Misirligil Z (2006) Does the combination of inhaled steroids with long acting $\beta_{2}$ agonists decrease the risk for osteoporosis? A 1-year prospective follow-up study. Rheumatol Int 27: 141-146.

Pytlik M, Folwarczna J, Janiec W (2004) Effects of doxycycline on mechanical properties of bones in rats with ovariectomy-induced osteopenia. Calcif Tissue Int 75: 225-230.

Radzki RP, Bieńko M, Kapica M, Puzio I, Dobrowolski P, Filip R (2006) Effect of $\beta_{2}$-adrenergic receptor agonist clenbuterol on the mineralization of tibiae in rats with established osteopenia. Medycyna Wet 62: 824-826 (in Polish).

Ryall JG, Plant DR, Gregorevic P, Sillence MN, Lynch GS (2004) $\beta_{2}$ Agonist administration reverses muscle wasting and improves muscle function in aged rats. J Physiol 555: 175-188.

Stuermer EK, Komrakova M, Werner C, Wicke M, Kolios L, Sehmisch S, Tezval M, Utesch C, Mangal O, Zimmer S, Dullin C, Stuermer KM (2010) Musculoskeletal response to whole-body vibration during fracture healing in intact and ovariectomized rats. Calcif Tissue Int 87: 168-180.

Stürmer EK, Seidlová-Wuttke D, Sehmisch S, Rack T, Wille J, Frosch KH, Wuttke W, Stürmer KM (2006) Standardized bending and breaking test for the normal and osteoporotic metaphyseal tibias of the rat: effect of estradiol, testosterone, and raloxifene. J Bone Miner Res 21: 89-96.

Śliwiński L, Folwarczna J, Nowińska B, Cegieła U, Pytlik M, Kaczmarczyk-Sedlak I, Trzeciak H, Trzeciak HI (2009) A comparative study of the effects of genistein, estradiol and raloxifene on the murine skeletal system. Acta Biochim Pol 56: 261-270.

Śliwiński L, Folwarczna J, Nowińska B, Trzeciak HI (2008) Differential effects of fenoterol on the skeletal system of non-ovariectomized and ovariectomized rats. Calcif Tissue Int 82 (Suppl 1): S225 (abstract).

Takeda S, Elefteriou F, Levasseur R, Liu X, Zhao L, Parker KL, Armstrong D, Ducy P, Karsenty G (2002) Leptin regulates bone formation via the sympathetic nervous system. Cell 111: 305-317.

Takeda S, Karsenty G (2008) Molecular bases of the sympathetic regulation of bone mass. Bone 42: 837-840.

Togari A, Arai M (2008) Pharmacological topics of bone metabolism: the physiological function of the sympathetic nervous system in modulating bone resorption. J Pharmacol Sci 106: 542-546.

Ton FN, Gunawardene SC, Lee H, Neer RM (2005) Effects of lowdose prednisone on bone metabolism. J Bone Miner Res 20: 464-470.

Turner CH, Burr DB (1993) Basic biomechanical measurements of bone: a tutorial. Bone 14: 595-608.

Vestergaard P, Rejnmark L, Mosekilde L (2007) Fracture risk in patients with chronic lung diseases treated with bronchodilator drugs and inhaled and oral corticosteroids. Chest 132: 1599-1607.

van Brussel MS, Bultink IEM, Lems WF (2009) Prevention of glucocorticoid-induced osteoporosis. Expert Opin Pharmacother 10: $997-$ 1005.

Westbroek I, Waarsing JH, van Leeuwen JP, Waldum H, Reseland JE, Weinans H, Syversen U, Gustafsson BI (2007) Long-term fluoxetine administration does not result in major changes in bone architecture and strength in growing rats. J Cell Biochem 101: 360-368.

Zeman RJ, Hirschman A, Hirschman ML, Guo G, Etlinger JD (1991) Clenbuterol, a $\beta_{2}$-receptor agonist, reduces net bone loss in denervated hindlimbs. Am J Physiol 261: E285-E289. 